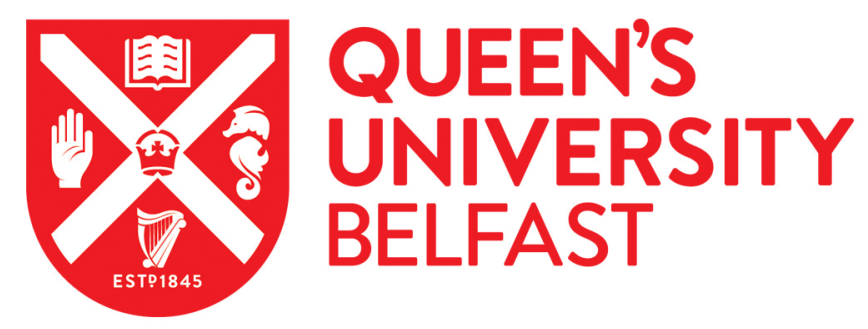

\title{
Effect of processing conditions on the structure, electrical and mechanical properties of melt mixed high density polyethylene/multi- walled CNT composites in compression molding
}

Xiang, D., Guo, J., Kumar, A., Chen, B., \& Harkin-Jones, E. (2017). Effect of processing conditions on the structure, electrical and mechanical properties of melt mixed high density polyethylene/multi-walled CNT composites in compression molding. Materials Testing, 59(2), 136-147. https://doi.org/10.3139/120.110974

Published in:

Materials Testing

Document Version:

Peer reviewed version

Queen's University Belfast - Research Portal:

Link to publication record in Queen's University Belfast Research Portal

Publisher rights

Copyright @ 2017 Carl Hanser Verlag GmbH \& Co. KG

This work is made available online in accordance with the publisher's policies.

\section{General rights}

Copyright for the publications made accessible via the Queen's University Belfast Research Portal is retained by the author(s) and / or other copyright owners and it is a condition of accessing these publications that users recognise and abide by the legal requirements associated with these rights.

Take down policy

The Research Portal is Queen's institutional repository that provides access to Queen's research output. Every effort has been made to ensure that content in the Research Portal does not infringe any person's rights, or applicable UK laws. If you discover content in the

Research Portal that you believe breaches copyright or violates any law, please contact openaccess@qub.ac.uk. 
Effect of processing conditions on the structure, electrical and mechanical properties of melt mixed high density polythylene/multi-walled carbon nanotubes nanocomposites

Dong Xiang ${ }^{\mathrm{a}, b^{*}}$, Eileen Harkin-Jones ${ }^{\mathrm{c}^{*}}$, Jiadong Guo ${ }^{\mathrm{a}}$, Zhenhua Chen ${ }^{\mathrm{a}}$, Qingquan Zhang ${ }^{\mathrm{a}}$, Amit Kumar ${ }^{\mathrm{d}}$, Biqiong Chen ${ }^{\mathrm{e}}$

aschool of Materials Science and Engineering, Southwest Petroleum University, 610500, China

bSchool of Mechanical and Aerospace Engineering, Queen’s University Belfast, BT9 5AH, UK

'School of Engineering, University of Ulster, BT37 0QB, UK

dSchool of Mathematics and Physics, Queen’s University Belfast, BT7 1NN, UK

eDepartment of Materials Science and Engineering, University of Sheffield, S1 3JD, UK

Abstract: Melt mixed high density polyethylene (HDPE)/multi-walled carbon nanotube (MWCNT) nanocomposites were prepared via twin-screw extrusion and then compression moulded into sheets. The effect of heating temperature, pressing time and cooling rate on the structure, electrical and mechanical properties of the compression moulded nanocomposites was systematically investigated. Volume resistivity tests indicate that the nanocomposite with $2 \mathrm{wt} \%$ MWCNTs, which is in the region of the electrical percolation threshold, is very sensitive to the compression moulding parameters such that heating temperature $>$ pressing time $>$ cooling rate. Generally, the resistivity of nanocomposites decreases with increasing heating temperature and pressing time. Interestingly, the electrical resistivity of the rapidly cooled nanocomposite with 2 wt $\%$ MWCNTs is $1 \sim 2$ orders lower than that of the slowly cooled nanocomposite with the same MWCNT loading. This can be attributed to the lower crystallinity and smaller crystallites facilitating the formation of conductive pathways. The 
tensile properties of the nanocomposite with $2 \mathrm{wt} \%$ MWCNTs are also influenced by the compression moulding parameters to some extent, while those of the nanocomposites with higher MWCNT loading are insensitive to the changes in processing conditions. The predicted moduli from Halpin-Tsai and Mori-Tanaka theoretical models show good agreement with the experimental results. This work has important implications for both process control and the tailoring of electrical and mechanical properties in the commercial manufacture of conductive HDPE/MWCNT nanocomposites.

Keywords: Polyethylene; Carbon nanotubes; Nanocomposites; Compression moulding; Processing

\section{Introduction}

In the last decade, carbon nanotubes (CNTs) have attracted great interest as multifunctional nanofillers for polymer nanocomposites as a result of their unique structure and excellent thermal, mechanical and electrical properties [1][2]-[4]. Enhanced properties can usually be obtained with the addition of a small amount of CNTs due to their very high aspect ratio. Polymer/CNT nanocomposites have a wide range of high-end applications, for instance, in polymeric solar cells, photovoltaic devices, electrochemical sensors, flat panel display screens, electrostatic charge dissipation (ESD) and electromagnetic interferenceshielding (EMI shielding) etc. [5][6][7]. However, the strong Van der Waals force between CNTs restricts their disentanglement and dispersion in a polymer matrix [2]. The presence of numerous CNT agglomerates can result in rather poor mechanical and electrical properties, thus uniform dispersion of CNTs is a significant pre-requisite for success in fabricating polymer/CNT nanocomposites with desirable properties [8]. In general, there are three main approaches to preparing polymer/CNT nanocomposites: in situ polymerization [9], solution mixing [10] and melt mixing [11], in which melt mixing is a simpler and more effective 
method, particularly from an industrial perspective [12]. In recent years, many studies on the melt mixing of CNTs into polymers have been carried out which indicate that the mixing effectiveness and the dispersion of CNTs depend on many factors including the affinity between CNTs and polymer [13], polymer viscosity [14], CNTs concentration [15], residence time [15], screw speed [15][16] and screw configuration [17].

High density polyethylene (HDPE) is an important, low cost, commodity thermoplastic. If the properties of HDPE could be enhanced via the addition of CNTs then the range of application areas for this material may be greatly extended. In the past few years, the dispersion, structure and properties of melt mixed HDPE/CNT nanocomposites have been extensively discussed in previous literature [18][19] [20] [21]. Morcom et al. [18] investigated the dispersion and reinforcing effect of multi-walled carbon nanotubes (MWCNTs) on the properties of a melt mixed HDPE/MWCNT composite. It was found that the MWCNTs with a larger diameter provided the highest reinforcement of $66 \%$ and $69 \%$ in elastic modulus and yield strength respectively at $5 \mathrm{wt} \%$ MWCNTs due to better nanotube dispersion. Verge et al. [19] compared the dispersion state of different types of MWCNTs in various grades of HDPE matrices by melt mixing. It was observed that each combination resulted in a different dispersion state so it is very difficult to universally predict the dispersion of nanotubes in a given HDPE matrix. Yang's [20] investigation of injection moulding of HDPE/MWCNT nanocomposites showed that MWCNTs nucleated HDPE crystal growth and induced a special transcrystalline microstructure (shish-kebab crystal) in a dynamic packing injection moulding (DPIM) process. Tao et al. [21] investigated the effect of shear-induced crystallization on the electrical properties of melt mixed HDPE/MWCNT composites. A similar transcrystalline structure to that observed in Yang's study [20] was also observed. It was found that the electrical conductivity of a composite shear-mixed for 20 minutes was significantly lower than that of sample mixed for 10 minutes due to the larger crystals which 
nucleated and grew on the nanotubes with increased shear-mixing time. These crystals prevented electrical contact between the nanotubes resulting in a decrease in electrical conductivity. Valentino et al. [22] prepared a series of HDPE/MWCNT nanocomposites with different loadings of MWCNTs using a micro-twin screw extruder. They observed a low electrical percolation threshold of between 1 to $2.5 \mathrm{wt} \%$ indicating an effective dispersion of nanotubes in the matrix.

Almost all the conventional polymer processing methods such as compression moulding, injection moulding, thermoforming, extrusion, blow moulding and blown film extrusion, can be used for processing polymer nanocomposites. Different processing routes and parameters to produce a product can result in a significant variation in the structure [23][24] and final properties of polymer nanocomposites [25], [26]. By way of example, the author's previous studies of biaxial stretching [2][3] and blown film extrusion [4] of melt mixed HDPE/MWCNT nanocomposites have shown that elongational deformation had a positive effect on the mechanical properties and a negative effect on the electrical conductivity of the composites due to the disentanglement and orientation of MWCNTs. After injection moulding, compression moulding is frequently used to form defined geometries such as plates [5]. Although many investigations on the effect of injection moulding conditions on structure and electrical properties have been presented for polymer/CNT composites [20][27][28], little attention has been paid to the effect of compression moulding parameters on the structure and properties of such nanocomposites. A knowledge of the influence of processing conditions on structure/properties of compression moulded nonocomposites is important for industrial applications but it is also very important for academic research as many samples for research investigations are produced using compression moulding. Little attention is generally paid to the processing conditions for these samples yet if the structure is influenced by processing, the properties will also be influenced 
and direct comparisons between results from various researchers using compression moulded samples will not be entirely valid. Kasaliwal et al. [5] investigated the effect of heating temperature and pressing time on the volume electrical resistivity of polycarbonate (PC)/MWCNT composites near the percolation threshold (1 wt\%). It was observed that the resistivity decreased with increasing heating temperature or pressing time due to the presence of more nanotube secondary agglomeration facilitated by enhanced molecular relaxation. Similar results were also shown in Yu's study [29] of the surface resistivity of ethylene-vinyl acetate (EVA) copolymer/MWCNT composites. The effect of the cooling rate utilised in compression moulding on the properties of CNT filled polymers has not to the authors' knowledge been investigated. Cooling conditions can vary in real industrial processing operations and in laboratory based investigations using compression moulding and it is important to know how robust the structuring (and properties) of nanocomposites is to such variations. This paper will therefore examine the influence of processing conditions, including cooling rates, on the structure and properties of compression moulded HDPE/CNT nanocomposites to help fill this missing gap in the literature.

In this paper, a high density polyethylene based MWCNT nanocomposite was prepared by melt mixing, using an industrial scale twin-screw extruder, at MWCNT loadings of 1 10 wt\%. The extruded pellets were compression moulded at different heating temperatures and pressing times followed by slow cooling (SC) or rapid cooling (RC) to produce sheets. The influence of processing conditions on the structure, electrical and mechanical properties of the resulting nanocomposite sheets was systematically investigated. As will be shown, heating temperature, pressing time and cooling rate in compression moulding can have a significant effect on the final mechanical and electrical properties of HDPE/CNT nanocomposites when operating in the electrical percolation threshold region. This suggests that good process control will be necessary in the commercial processing of such 
nanocomposites as companies will seek to operate near the percolation threshold to reduce costs. It also points to the need for standardised testing in research laboratories using compression moulding to produce test plaques so that valid comparisons of results can be made between laboratories.

\section{Experimental}

\subsection{Materials}

High density polyethylene, grade HDPE HTA-108, in pellet form was obtained from ExxonMobil. It has an average molecular weight of 123,400 g/mol and a density of 0.961 $\mathrm{g} / \mathrm{cm} 3$. The melt flow index (MFI) of the HDPE is $0.7 \mathrm{~g} / 10 \mathrm{~min}\left(190{ }^{\circ} \mathrm{C} / 2.16 \mathrm{~kg}\right)$. Multiwalled carbon nanotubes (Nanocyl NC7000) with a purity of $90 \%$, produced via catalytic chemical vapour deposition, were kindly supplied by Nanocyl SA, Belgium. The nanotubes have a nominal diameter of $9.5 \mathrm{~nm}$ and a nominal average length of $1.5 \mu \mathrm{m}$ [30]. The density of the nanotubes is $1.85 \mathrm{~g} / \mathrm{cm}^{3}$ [18].

\subsection{Preparation and processing}

The HDPE pellets were ground, at room temperature, into a powder using a Wedco SE12 UR pilot plant grinder operating at $7000 \mathrm{rpm}$ and with a gap size set to $400 \mu \mathrm{m}$. The HDPE powder was premixed with the MWCNTs using a PRISM Pilot 3 high speed mixer at MWCNT loadings of 1 10 wt\%. The dry blends were melt mixed in a Collin ZK 25 twinscrew extruder with a 30:1 length to diameter ratio (L/D) and a temperature profile of 175 , $220,220,215,210,200{ }^{\circ} \mathrm{C}$ from zones 1 to 6 . The screw speed was set at $150 \mathrm{rpm}$ and the feeding rate was $25 \%$. The residence time of melt in the extruder is about $1.5 \mathrm{~min}$. The extruded strand was cooled in a water bath and pelletized. Some strands of the extrudate were 
retained for microscopic analysis and electrical resistivity testing. It should be noted that the nanocomposite with $2 \mathrm{wt} \%$ MWCNTs is denoted as CNT2 in this paper, and so forth.

The pellets were compression moulded in a steel mould of $1 \mathrm{~mm}$ thickness using a Dr. Collin P200P platen press at various heating temperatures, pressing times and cooling rates, to investigate the effect of compression moulding parameters on the structure, electrical and mechanical properties of the HDPE/MWCNT nanocomposites. Detailed processing parameters are listed in Table 1. The internal heating temperature of the mould cavity and cooling rates were verified using a thermocouple placed in the middle of the sample. The measured temperature profiles are shown in Figure 1. It should be noted that in this work the pressing time only includes the heating-up time and holding time, and the pressing pressure is kept constant during the entire compression moulding process.

Table 1 Compression moulding parameters for the HDPE/MWCNT nanocomposites.

\begin{tabular}{lllll}
\hline Processing code & Heating temperature $\left({ }^{\circ} \mathrm{C}\right)$ & Pressing time $(\mathrm{min})$ & Cooling rate $\left({ }^{\circ} \mathrm{C} / \mathrm{min}\right)$ & Pressing pressure (bar) \\
\hline $\mathrm{CM} / 150 / 3 / \mathrm{SC}$ & 150 & 3 & 20 & \\
$\mathrm{CM} / 150 / 5 / \mathrm{SC}$ & 150 & 5 & 20 & \\
$\mathrm{CM} / 200 / 3 / \mathrm{SC}$ & 200 & 3 & 20 & \\
$\mathrm{CM} / 200 / 5 / \mathrm{SC}$ & 200 & 5 & 20 & 100 \\
$\mathrm{CM} / 150 / 3 / \mathrm{RC}$ & 150 & 3 & 300 & \\
$\mathrm{CM} / 150 / 5 / \mathrm{RC}$ & 150 & 5 & 300 \\
$\mathrm{CM} / 200 / 3 / \mathrm{RC}$ & 200 & 3 & 300 \\
$\mathrm{CM} / 200 / 5 / \mathrm{RC}$ & 200 & 5 & 300 \\
\hline
\end{tabular}




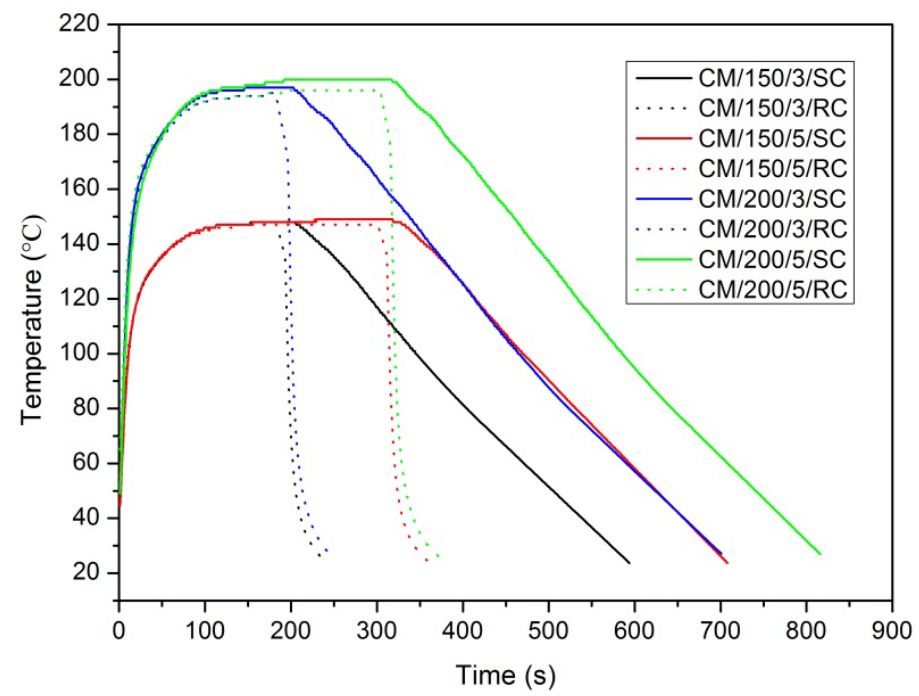

Figure 1 Measured temperature profiles in the mould cavity.

\subsection{Characterization}

\subsubsection{Scanning electron microscopy (SEM)}

The samples were first plasma etched for $1 \mathrm{~min}$ at an etching power of $100 \mathrm{~W}$ using a reactive ion etching system (STS Cluster C005) to remove the amorphous phase of the polymer matrix in order to observe the morphology of the nanotubes more clearly. The plasma etched samples were gold sputtered and then examined using a JEOL 6500F SEM with an operating voltage of $5.0 \mathrm{kV}$.

\subsubsection{High resolution transmission electron microscopy (HRTEM)}

The dispersion of MWCNTs in the compression moulded nanocomposite sheets produced at different cooling rates was further examined using a FEI Tecnai G2 Spirit TEM at $100 \mathrm{kV}$. Ultrathin sections with a thickness of less than $100 \mathrm{~nm}$ were cryo-ultramicrotomed using a Leica EMUG6 ultramicrotome.

\subsubsection{Conductive atom force microscopy (CAFM)}

Microscopic current measurements for the compression moulded composite sheets with different cooling rates were performed using a Dimension 3100 CAFM equipped with a 
TUNA head in contact mode at a bias of $1 \mathrm{~V}$. A Pt-coated PPP-EFM tip and silicon cantilever were used in the CAFM tests.

\subsubsection{Wide angle X-ray diffraction (XRD)}

Wide-angle X-ray diffraction was performed using a PANalytical X'Pert PRO diffractometer to characterise the structure of the compression moulded samples. $\mathrm{Cu}-\mathrm{K} \alpha$ radiation with a wavelength of $1.54 \AA$ was used. Data were recorded from 2 to $60^{\circ}$ with a step size of $0.016^{\circ}(2 \theta)$ and a scan speed of $0.021 \%$ s. Jade XRD analysis software was employed to analyse the experimental data. The crystallinity of nanocomposites was obtained by calculating the areas of the amorphous and crystalline phases (Equation 1). The average crystallite sizes ( $L_{110}$ and $L_{200}$ ) in (110) and (200) were calculated using the Scherrer equation (Equation 2) [31].

$$
X_{C}=\frac{I_{C}}{I_{A}+I_{C}} \times 100 \%
$$

where $I_{C}$ is the crystalline area, and $I_{A}$ is the amorphous area.

$$
L_{h k l}=\frac{K \lambda}{\beta \cos \theta}
$$

where $K$ is the shape factor of the crystal, $\lambda$ is the wavelength of incident X-ray ( $\lambda=$ $0.15405 \mathrm{~nm}), \beta$ is the full width at half maximum of the $h k l$ peak and $\theta$ is the incident angle.

\subsubsection{Differential scanning calorimetry (DSC)}

A Perkin-Elmer DSC model 6 was used to measure the percentage crystallinity, melting and crystallization behaviour of the HDPE and HDPE/MWCNT nanocomposites under an inert nitrogen atmosphere. Samples with a typical mass of 7 10 mg were cut from the middle of the compression moulded sheets. The samples were heated from $30{ }^{\circ} \mathrm{C}$ to $200{ }^{\circ} \mathrm{C}$ at a heating rate of $10{ }^{\circ} \mathrm{C} / \mathrm{min}$, held at $200{ }^{\circ} \mathrm{C}$ for $3 \mathrm{~min}$, followed by a cooling process from $200{ }^{\circ} \mathrm{C}$ 
to $30{ }^{\circ} \mathrm{C}$ at a cooling rate of $10{ }^{\circ} \mathrm{C} / \mathrm{min}$. Then the samples were reheated to $200{ }^{\circ} \mathrm{C}$ again at $10{ }^{\circ} \mathrm{C} / \mathrm{min}$. The melting temperatures in both heating processes and the crystallization temperature in the cooling process were recorded. Three repeated tests were conducted for each sample.

In this work, the heat of fusion of $100 \%$ HDPE crystal $\left(\Delta H_{m}^{\circ}\right)$ was taken as $293 \mathrm{~J} / \mathrm{g}$ [32], and then the degree of crystallinity $(X c)$ was calculated using Equation 3:

$$
X c=\frac{\Delta H_{m}}{\left(1-M_{C N T}\right) \Delta H_{m}^{\circ}} \times 100 \%
$$

where $\Delta H_{m}$ is the enthalpy of fusion of sample ( $\left.\mathrm{J} / \mathrm{g}\right) ; M_{C N T}$ is the weight fraction of carbon nanotubes.

\subsubsection{Electrical resistivity testing}

Volume electrical resistivity testing was carried out for the extruded and compression moulded samples. For the samples with a high resistivity $\left(>10^{8} \Omega\right)$, volume resistivity testing was performed using a Keithley 6517A high resistivity electrometer equipped with a Keithley 8009 resistivity test fixture according to ASTM-D257. In this method, the circular samples cut from the compression moulded sheets have a diameter of $70 \mathrm{~mm}$. For more conductive samples $\left(\leq 10^{8} \Omega\right)$, two-point probe measurements were conducted using a Keithley DMM2000 multimeter. In the two-point probe measurements, strips with dimensions of 50 $\mathrm{mm} \times 10 \mathrm{~mm}$ were cut from the compression moulded sheets, and cylindrical specimens with dimensions of $\varnothing 2.5 \mathrm{~mm} \times 10 \mathrm{~mm}$ were cut from the extruded strands. Silver paste was introduced to minimise contact resistance . Two specimens for each type were tested, and the average value was calculated.

\subsubsection{Tensile testing}


Tensile tests were conducted for the compression moulded sheets using an Instron 5564 Universal Tester at room temperature (BS EN ISO 527:1996). The test samples were cut from the middle of the sheets. Young's modulus and stress at yield were determined using a clip-on extensometer at a crosshead speed of $5 \mathrm{~mm} / \mathrm{min}$. Stress at break and strain at break were taken at a crosshead speed of $50 \mathrm{~mm} / \mathrm{min}$. Five samples were tested for each sheet and average values were calculated.

\section{Results and discussion}

\subsection{Morphological analysis}

Figure 2 shows the morphologies of extruded and compression moulded composites containing 2 wt $\%$ and 4 wt\% MWCNTs. The SEM image shown in Figure 2a is from the extruded sample taken in the extrusion direction. It can be observed in Figure 2a that the MWCNTs align along the material flow direction, while the polymer lamellae are perpendicular to the flow direction. A similar alignment of nanotubes along the flow direction was also observed in other literature [33][34]. From Figure 2b for the compression moulded samples at $150{ }^{\circ} \mathrm{C}$ for $3 \mathrm{~min}$ followed by a SC (CM/150/3/SC) one can see the individual nanotubes and that agglomerates have not formed obvious network structures yet. The polymer lamellae are also randomly aligned. A network-like structure of nanotubes can be observed in Figure 2c and Figure 2d due to the relaxation of nanotubes after compression moulding at $200{ }^{\circ} \mathrm{C}$ for 3 and 5 min respectively, followed by SC (CM/200/3/SC and CM/200/5/SC). These individual MWCNTs and secondary agglomerates which can enhance the formation of conductive networks [14] are homogeneously distributed in the HDPE matrix. From Figure 2c and Figure 2d, it appears that the nanocomposite containing 2 wt\% MWCNTs compression moulded at $200{ }^{\circ} \mathrm{C}$ for $5 \mathrm{~min}$ is apt to form larger nanotube agglomerates compared to that compression moulded at $200{ }^{\circ} \mathrm{C}$ for $3 \mathrm{~min}$ as a result of the 
increased relaxation time for the MWCNTs. Figure 2e shows the morphology of the nanocomposite containing $2 \mathrm{wt} \%$ MWCNTs compression moulded at $200{ }^{\circ} \mathrm{C}$ for $5 \mathrm{~min}$ followed by RC (CM/200/5/RC). The polymer lamellae are less clear due to the presence of numerous imperfect crystallites. This is also supported by the XRD and DSC results in the next section. More compact secondary agglomerates can be observed in Figure $2 \mathrm{f}$ for the nanocomposite containing $4 \mathrm{wt} \%$ MWCNTs compression moulded at $200{ }^{\circ} \mathrm{C}$ for 5 min followed by SC, indicating that it is more difficult to disperse this loading of nanotubes in the high viscosity matrix.
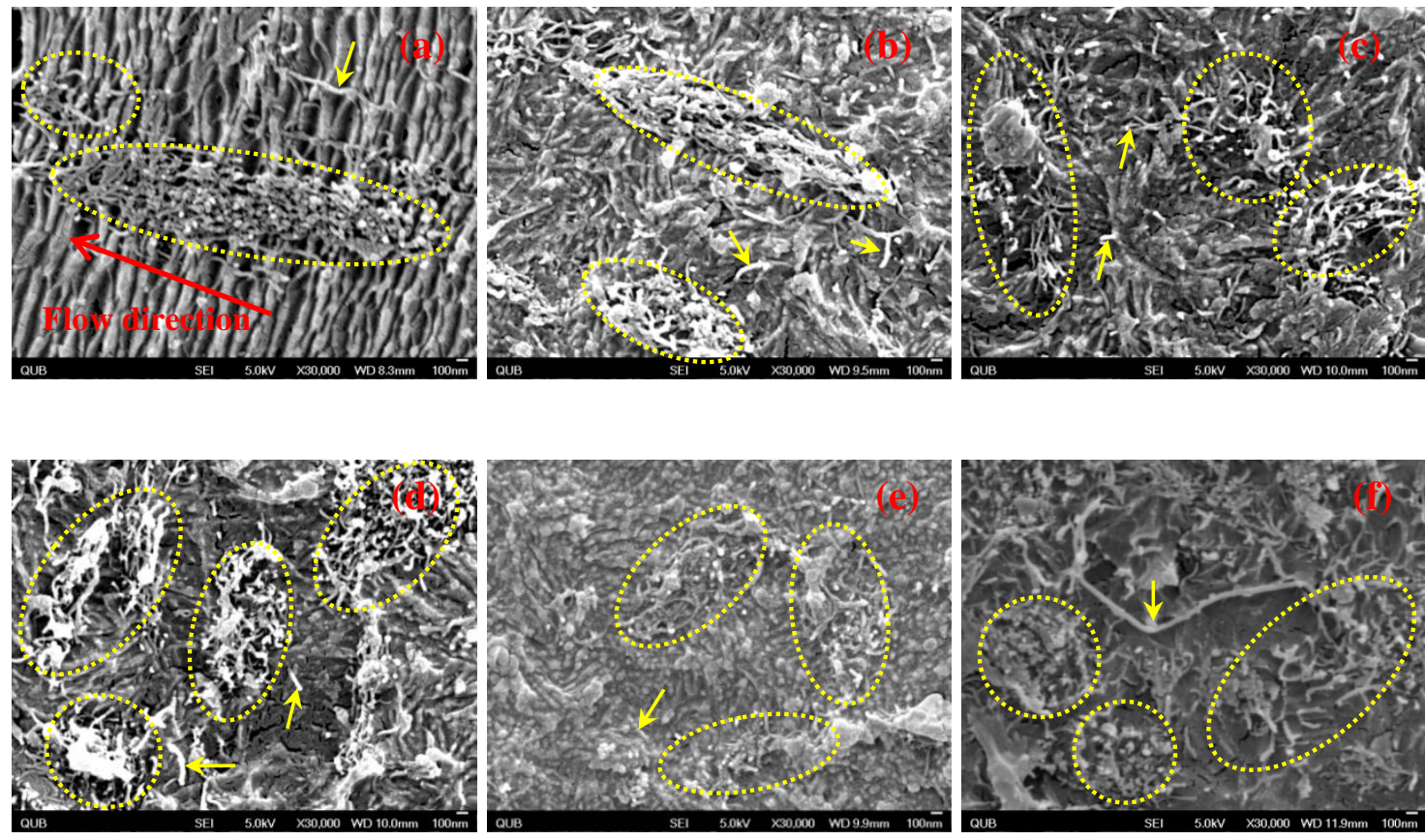

Figure 2 SEM micrographs of the HDPE/MWCNT nanocomposites at different compression moulding conditions and MWCNT loadings: (a) extruded, 2 wt\% MWCNTs; (b) CM/150/3/SC, 2 wt\% MWCNTs; (c) CM/200/3/SC, 2 wt\% MWCNTs; (d) CM/200/5/SC, 2 wt\% MWCNTs; (e) CM/200/5/RC, 2 wt\% MWCNTs; (f) CM/200/5/SC, 4 wt\% MWCNTs (the agglomerated nanotubes are circled and the individual nanotubes are indicated by arrows in the micrographs). 
In order to more clearly observe the dispersion and morphological details of nanocomposites under SC and RC, TEM tests were also conducted for the HDPE/MWCNT nanocomposites with $2 \mathrm{wt} \%$ MWCNTs compression moulded at $200^{\circ} \mathrm{C}$ for 5 min followed by SC and RC, as shown in Figure 3. It can be seen in Figure 3a and Figure 3b that the nanocomposite under SC has a less homogeneous dispersion state of MWCNTs with larger secondary nanotube agglomerates compared to that under RC. This can be mainly attributed to an increased relaxation time for the MWCNTs to agglomerate in the polymer matrix under SC.
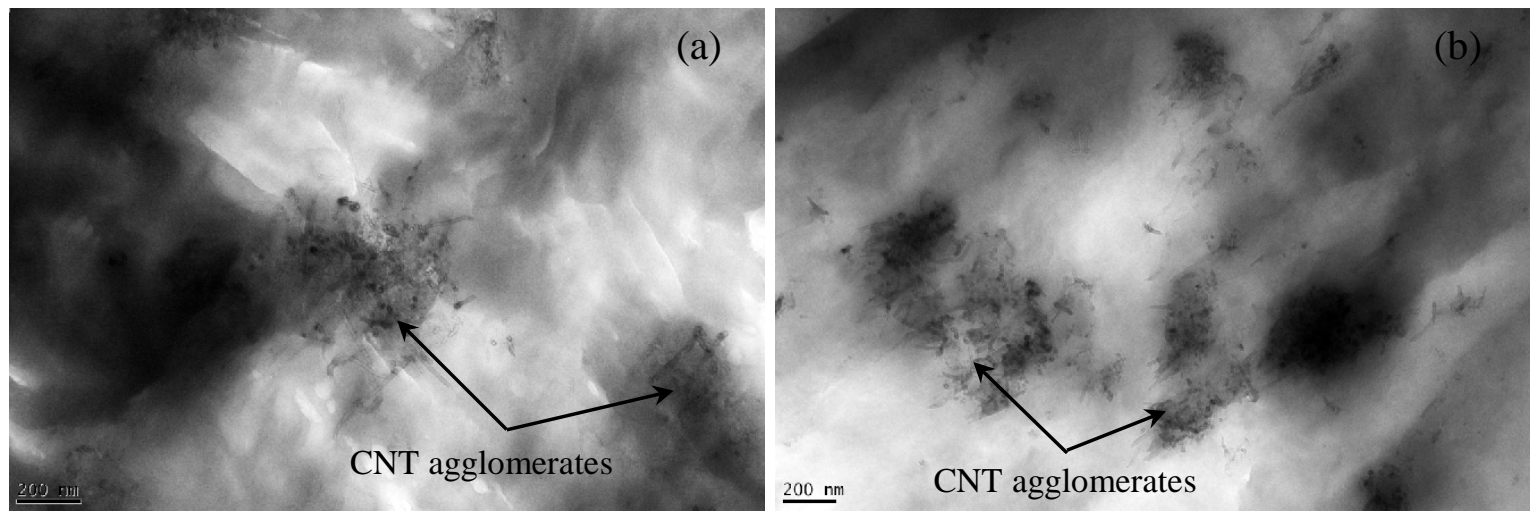

Figure 3 TEM micrographs of the HDPE/MWCNT nanocomposites with 2 wt\% MWCNTs compression moulded at $200{ }^{\circ} \mathrm{C}$ for 5 min followed by SC (a) and RC (b).

\subsection{XRD and DSC results}

The crystallization behaviour of the polymer matrix can be markedly influenced by the cooling rates, while it may be independent on the heating temperatures and pressing time during compression moulding. The crystallinity and average crystallite sizes of the compression moulded nanocomposites at different cooling rates can be shown by XRD and DSC. Figure 4a and Figure 4b respectively show the XRD patterns and DSC thermograms of the HDPE/MWCNT nanocomposites compression moulded at $200{ }^{\circ} \mathrm{C}$ for 5 min followed by SC and RC. It can be seen in Figure 4a that the HDPE exhibits a strong reflection peak at 
$21.6^{\circ}$, followed by a less intensive peak at $24.0^{\circ}$, which correspond to the typical orthorhombic unit cell structure of the (110) and (200) reflection planes respectively. The XRD pattern of MWCNTs shows a reflection peak at $25.6^{\circ}$ derived from the ordered arrangement of concentric cylinders of MWCNTs [35], as shown in the insert of Figure 4a. The average crystallite sizes ( $L_{110}$ and $L_{200}$ ) in (110) and (200) calculated according to Scherrer equation [31] and crystallinity $\left(\boldsymbol{X}_{\boldsymbol{X} R \boldsymbol{D}}\right)$ from XRD are listed in Table 2 . The reduced crystallinity and crystallite sizes of all the samples after RC indicate that it had a suppression effect on the polymer mobility [36]. The XRD results are supported by the DSC results in the first heating stage. Figure $4 \mathrm{~b}$ shows that the melting peaks in the first heating stage of DSC testing for the samples after RC shifts to a lower temperature, indicating a decreased melting temperatures $\left(T_{m}^{1 s t}\right)$ due to the smaller crystallites formed. The crystallinity in the first heating stage $\left(X_{D S C}^{1 s t}\right)$ also decreases after RC according to the DSC results. However, there is no significant difference in the crystallinity $\left(X_{D S C}^{2 n d}\right)$ and melting temperature $\left(T_{m}^{2 n d}\right)$ from the second heating stage of DSC testing between the samples after SC and RC due to the removal of the processing history. The crystallization temperature $\left(T_{c}\right)$ increases by about $2{ }^{\circ} \mathrm{C}$ with the addition of MWCNTs, indicating that MWCNTs are acting as nucleation sites [37]. The detailed melting temperatures, crystallization temperatures and crystallinity from DSC are also shown in Table 2. 

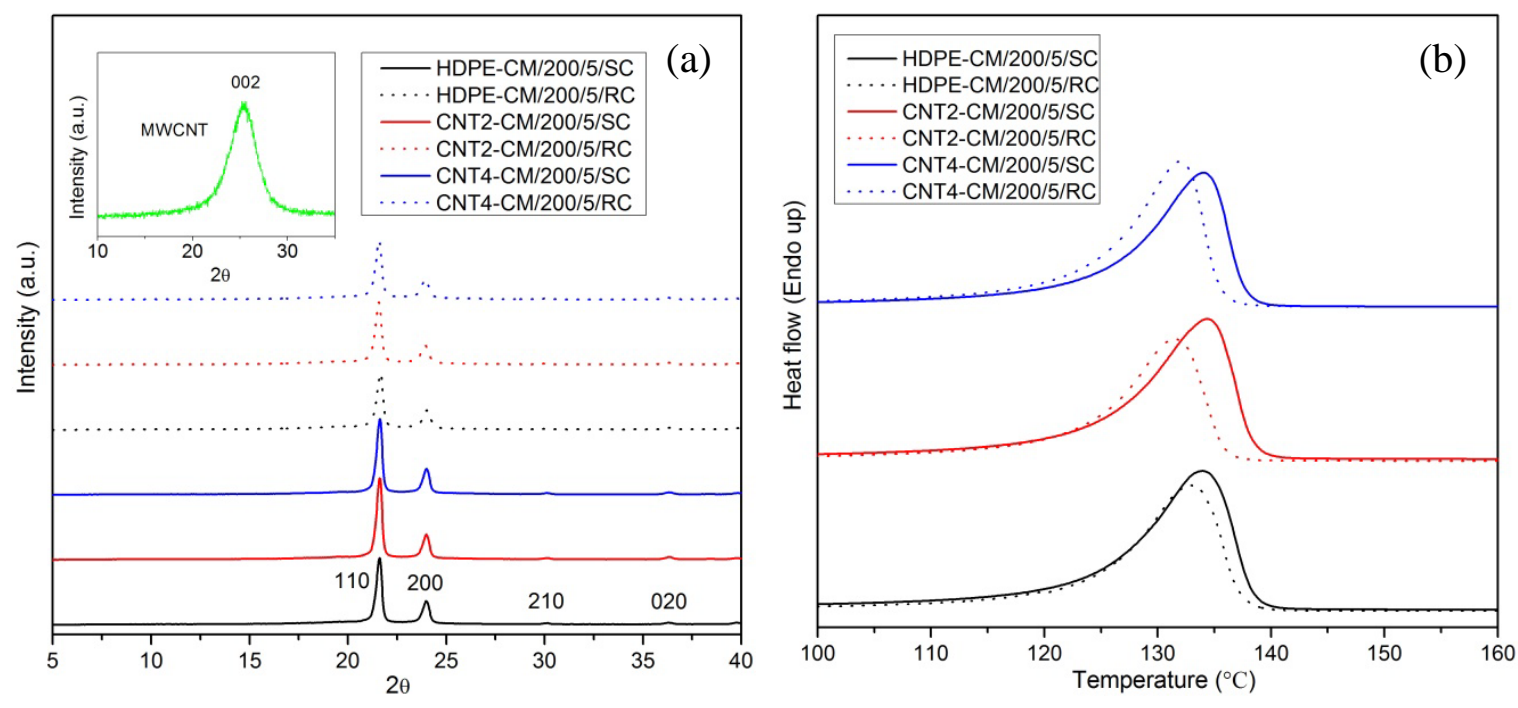

Figure 4 XRD patterns (a) and DSC thermograms in the $1^{\text {st }}$ heating stage (b) of HDPE/MWCNT nanocomposites compression moulded at $200{ }^{\circ} \mathrm{C}$ for $5 \mathrm{~min}$ followed by SC and RC (the curves in this figure are vertically offset for clarity).

Table 2 XRD and DSC results of HDPE/MWCNT nanocomposites compression moulded at $200{ }^{\circ} \mathrm{C}$ for 5 min followed by SC and RC.

\begin{tabular}{|c|c|c|c|c|c|c|c|c|}
\hline \multirow[b]{2}{*}{ Sample } & \multicolumn{3}{|c|}{ XRD } & \multicolumn{5}{|c|}{ DSC } \\
\hline & $\begin{array}{c}X_{X R D} \\
(\%)\end{array}$ & $\begin{array}{l}L_{110} \\
(\mathrm{~nm})\end{array}$ & $\begin{array}{l}L_{200} \\
(\mathrm{~nm})\end{array}$ & $\begin{array}{l}X_{D S C}^{1 s t} \\
(\%)\end{array}$ & $\begin{array}{l}T_{m}^{1 s t} \\
\left({ }^{\circ} \mathrm{C}\right)\end{array}$ & $\begin{array}{l}T_{c} \\
\left({ }^{\circ} \mathrm{C}\right)\end{array}$ & $\begin{array}{l}X_{D S C}^{2 n d} \\
(\%)\end{array}$ & $\begin{array}{l}T_{m}^{2 n d} \\
\left({ }^{\circ} \mathrm{C}\right)\end{array}$ \\
\hline HDPE-CM/200/5/SC & 71.5 & 27.3 & 22.5 & $74.0( \pm 1.9)$ & $133.9( \pm 0.2)$ & $114.0( \pm 0.2)$ & $70.4( \pm 1.3)$ & $134.1( \pm 0.1)$ \\
\hline HDPE-CM/200/5/RC & 65.8 & 24.0 & 19.8 & $66.5( \pm 2.5)$ & $132.8( \pm 0.2)$ & $113.6( \pm 0.2)$ & $71.4( \pm 2.0)$ & $134.8( \pm 0.3)$ \\
\hline CNT2-CM/200/5/SC & 71.9 & 28.3 & 22.8 & $71.4( \pm 4.1)$ & $134.4( \pm 0.3)$ & $115.7( \pm 0.5)$ & $69.2( \pm 2.2)$ & $134.6( \pm 0.4)$ \\
\hline CNT2-CM/200/5/RC & 62.8 & 25.1 & 20.4 & $69.2( \pm 1.8)$ & $131.9( \pm 0.5)$ & $115.5( \pm 0.1)$ & $70.8( \pm 3.2)$ & $134.9( \pm 0.4)$ \\
\hline CNT4-CM/200/5/SC & 71.0 & 27.7 & 23.2 & $73.0( \pm 4.8)$ & $134.0( \pm 0.1)$ & $116.0( \pm 0.2)$ & $70.7( \pm 2.4)$ & $134.3( \pm 0.2)$ \\
\hline CNT4-CM/200/5/RC & 62.7 & 24.8 & 20.3 & $68.0( \pm 2.4)$ & $132.1( \pm 0.3)$ & $115.6( \pm 0.2)$ & $70.2( \pm 2.3)$ & $134.7( \pm 0.2)$ \\
\hline
\end{tabular}

\subsection{Electrical properties}

The electrical properties of HDPE/MWCNT nanocomposites made at different heating temperatures and pressing time followed by SC were characterized by measuring the volume resistivity of extruded and compression moulded samples, as shown in Figure 5. According to 
the classic percolation theory of highly dispersed conductive additives in an isolating polymer matrix, conductive fillers can form conductive networks in the bulk of the matrix thus causing a decrease of the resistivity when the content of the conductive additive reaches the percolation threshold. In this work, it can be observed that the resistivity of extruded strands with 2 wt\% MWCNTs is still beyond the full scale of the multimeter showing a high resistance $\left(>10^{8} \Omega\right)$, but it decreases when the MWCNT loading reaches $4 \mathrm{wt} \%$. Furthermore, the resistivity of all the extruded strands is higher than that of the compression moulded nanocomposites. The difference in resistivity between the extruded and compression moulded samples may be attributed to the difference in alignment of the MWCNTs in the samples (Figure 2) with alignment being greater in the extruded strands and thus having a lower potential to form a conductive network [38].

The scaling law of classical percolation theory (Equation 4) [33] was used to further analyse the conductive network in the HDPE/MWCNT nanocomposites:

$$
\rho \propto\left(\phi-\phi_{t}\right)^{-t}
$$

where $\phi$ is the filler weight fraction, $\rho$ is the volume resistivity of the nanocomposite, $\phi_{t}$ is the critical concentration and $t$ is the critical exponent which reflects the dimensionality of the conductive network in the system. It follows a power-law dependence of approximately 1 1.3 in a two dimensional system and 1.6 2 in a three dimensional system [39]. The critical concentration $\phi_{t}$ and the critical exponent $t$ of the nanocomposites were determined by a least square fitting of the experimental data in MATLAB, and the results are listed in Table 3. One can see a critical concentration of 3.9 wt\% and a critical exponent of 1.3 for the extruded nanocomposites. This low critical exponent indicates that the extruded nanocomposites generally follow a two dimensional model due to the restraint for charge transportation between the MWCNTs in the transverse direction [3]. The critical 
concentration decreases and the critical exponent increases with increasing heating temperatures and pressing time. The nanocomposite compression moulded at a heating temperature of $200{ }^{\circ} \mathrm{C}$ and a pressing time of 5 min followed by SC shows a critical concentration of $1.9 \mathrm{wt} \%$ and a critical exponent of 1.9. It is evident that the decrease in critical concentration means an improvement in conductivity in the compression moulded samples, and the increase in critical exponent reveals the steady transformation from a two dimensional system to a three dimensional system after compression moulding.

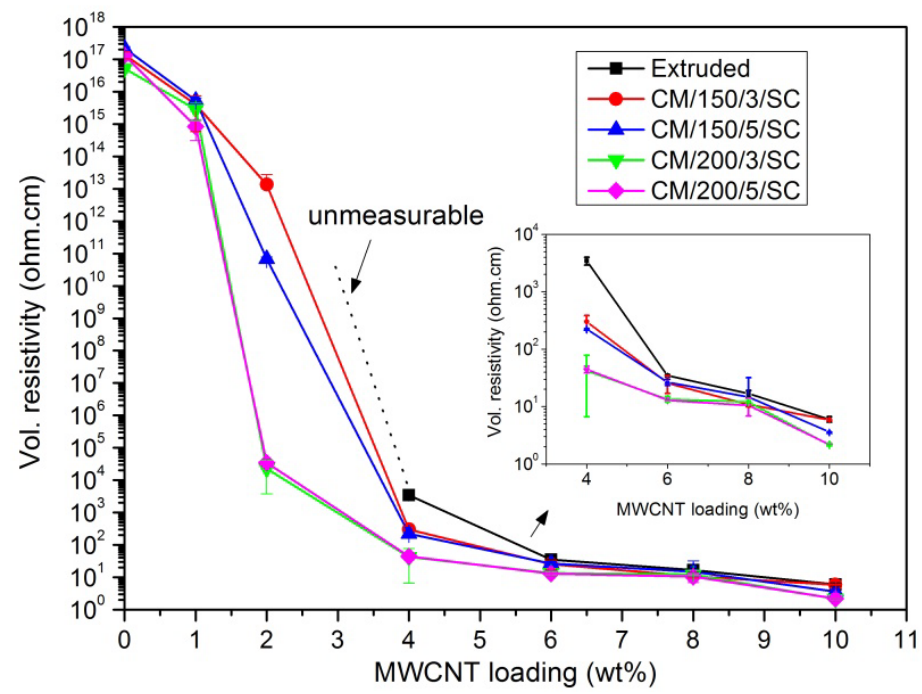

Figure 5 Volume resistivity of extruded HDPE/MWCNT nanocomposites and compression moulded HDPE/MWCNT nanocomposites with different heating temperatures and pressing time followed by SC as a function of MWCNT loading (Inset: a partial enlarged view for the resistivity of the nanocomposites containing 4 8 wt\% MWCNTs).

Table 3 Critical concentration $\phi_{t}$ and critical exponent $t$ for the extruded nanocomposites and compression moulded nanocomposites at SC.

\begin{tabular}{lccccc}
\hline Percolation parameters & Extruded & CM/150/3/SC & CM/150/5/SC & CM/200/3/SC & CM/200/5/SC \\
\hline$\phi_{t}$ (wt\%) & 3.9 & 3.5 & 3.3 & 2.0 & 1.9 \\
$t$ & 1.3 & 1.5 & 1.5 & 1.7 & 1.9 \\
\hline
\end{tabular}


It can be seen in Figure 5 that the electrical properties of nanocomposites with a MWCNT loading in the percolation threshold region are significantly influenced by compression moulding conditions. The details of the resistivity of nanocomposites containing 1, 2 and 4 wt\% MWCNTs are shown in Figure 6, and the volume electrical resistivity of nanocomposites compression moulded at SC and RC are compared. It can be observed that the resistivity of the nanocomposite containing $2 \mathrm{wt} \%$ MWCNTs decreases by $6 \sim 9$ orders of magnitude when the heating temperature increases from 150 to $200{ }^{\circ} \mathrm{C}$. The pressing time only has an evident effect on the resistivity of the nanocomposite with 2 wt\% MWCNTs compression moulded at $150{ }^{\circ} \mathrm{C}$, and the resistivity of the nanocomposite decreases by 3 orders of magnitude when the pressing time increases from $3 \mathrm{~min}$ to $5 \mathrm{~min}$ at this heating temperature irrespective of cooling rate. It appears that a pressing time of $3 \mathrm{~min}$ is sufficient for the nanocomposite containing $2 \mathrm{wt} \%$ MWCNTs to complete the construction of conductive network at $200{ }^{\circ} \mathrm{C}$, therefore there is no significant change in the resistivity of the nanocomposite when the pressing time increases from 3 to $5 \mathrm{~min}$ at this temperature. Interestingly, the electrical resistivity of the rapidly cooled nanocomposites with 2 wt\% MWCNTs is 1 2 orders lower than that of the slowly cooled nanocomposites with the same MWCNT loading. This should not be simply attributed to the increased nanotube agglomerate size under SC (Figure 3) with longer relaxation time for the MWCNTs otherwise one would expect that the resistivity of nanocomposites compression moulded at $200{ }^{\circ} \mathrm{C}$ would increase with increasing pressing time. This is obviously in conflict with the experimental results shown in Figure 6. 


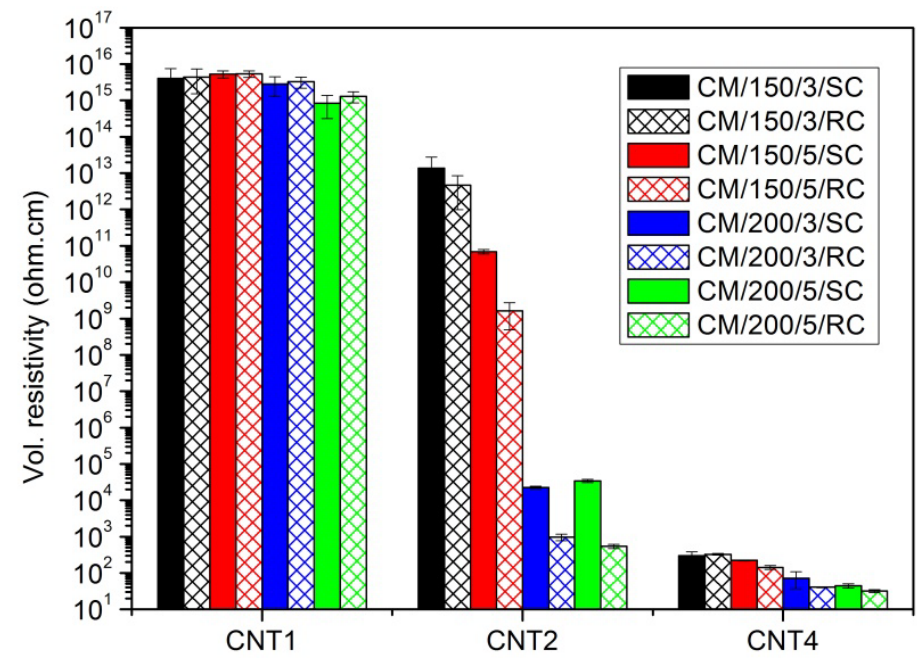

Figure 6 Resistivity variations of the HDPE/MWCNT nanocomposites under different compression moulding conditions.

In order to further analyse the reason for the decrease in resistivity at RC, microscopic current measurements for the nanocomposite with $2 \mathrm{wt} \%$ MWCNTs compression moulded at $200{ }^{\circ} \mathrm{C}$ for 5 min followed by SC and RC were performed using a CAFM. The CAFM tip measures the current throughout the volume of the nanocomposite specimen at a given voltage, which is running via the nanotube network to the ground contact. Only nanotubes that are connected with the ground contacts can be monitored. The current distribution images from the CAFM tests are shown in Figure 7. These bright spots and patches in Figure 7 reflect the regions with a high current density which mainly involve the secondary nanotube agglomerates in the matrix. In previous literature [5][14], it has been proposed that these secondary agglomerates can facilitate the formation of conductive networks. However, to the best of our knowledge, in this work this is the first time to directly confirm the significance of secondary nanotube agglomerates in the formation of conductive networks in a polymer by CAFM. It can be observed in Figure 7 that the nanocomposite containing 2 wt\% MWCNTs under RC exhibits a slightly higher maximum current of $20.77 \mathrm{nA}$ and more conductive regions uniformly distributed in the matrix compared to that under SC, indicating more 
conductive networks formed. This may be due to the lower crystallinity and smaller crystallites at RC facilitating the formation of conductive pathways [21][40]. The information on the crystallinity and crystallite sizes of HDPE/MWCNT nanocomposites was presented via the XRD and DSC results in the previous section (Table 2). Numerous imperfect crystallites for the nanocomposite under RC can be observed in the SEM image (Figure 2e). In contrast, with respect to the nanocomposite containing $2 \mathrm{wt} \%$ MWCNTs under SC, the conductive pathways formed in the heating-up and holding stages during compression moulding are more readily interrupted under SC due to the increase in the number and size of crystallites which would be located between the secondary nanotube agglomerates. This would result in fewer secondary nanotube agglomerates being connected in a conductive network and a relatively higher resistivity than the nanocomposite under RC. It is reasonable that a slight change in the crystal structure of the polymer can influence the resistivity of the nanocomposite because the critical maximum distance for electron hopping between the nanotubes is just about $1.8 \mathrm{~nm}$ [41]. A schematic diagram of the conductive pathways formed in the nanocomposite with a MWCNT loading in the region of the electrical percolation threshold under SC and RC is shown in Figure 8.

The effect of cooling rate on resistivity is much less significant for the nanocomposite with $4 \mathrm{wt} \%$ MWCNTs as a result of the abundant conductive networks formed in the HDPE matrix. This result indicates that cooling rate can be a significant parameter in influencing electrical conductivity when operating in the region of the percolation threshold. 

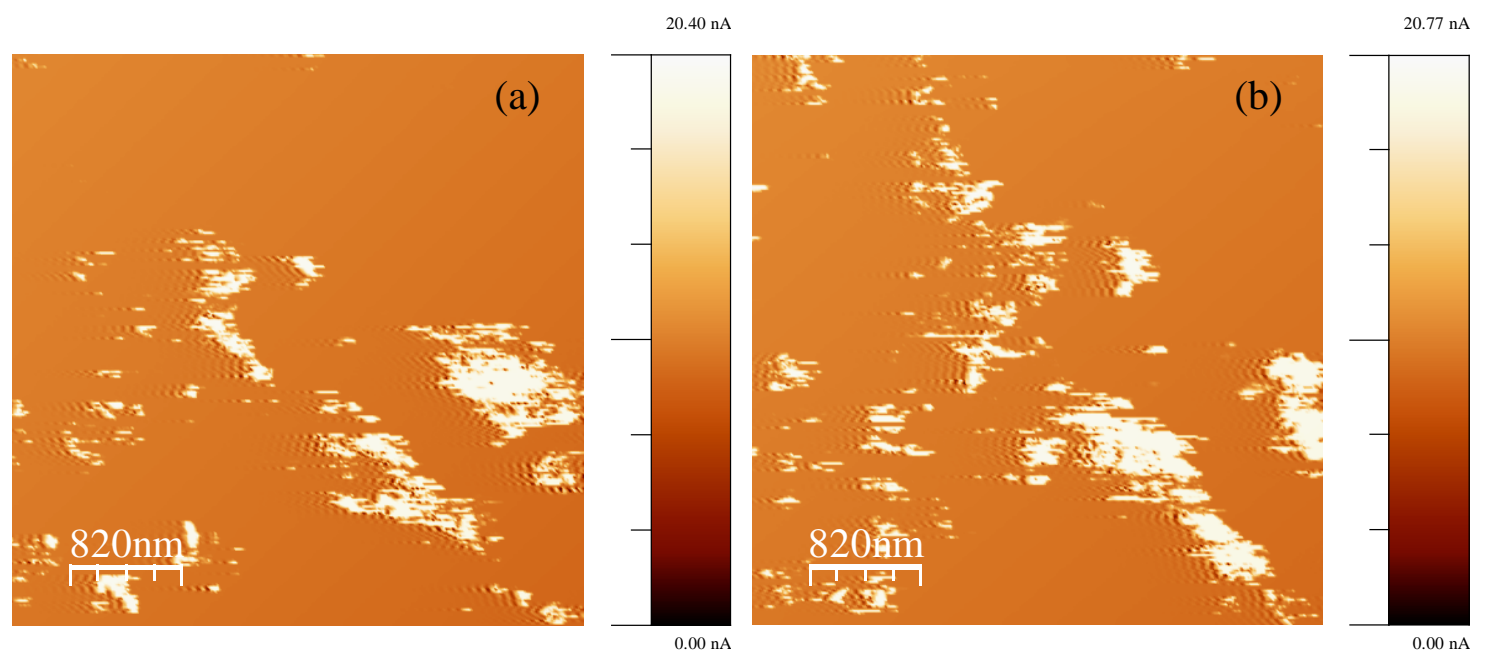

Figure 7 Current distribution images for the nanocomposite samples with 2 wt\% MWCNTs compression moulded at $200{ }^{\circ} \mathrm{C}$ for 5 min followed by SC (a) and RC (b).

(a)

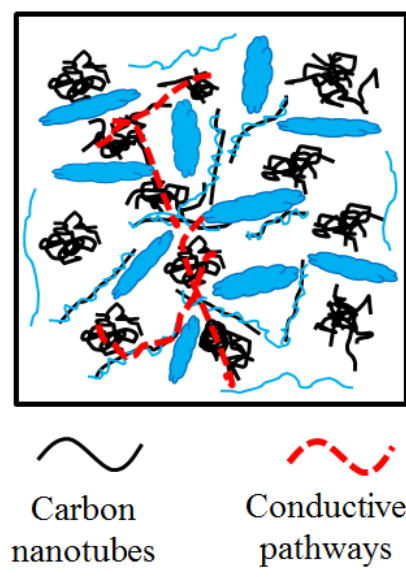

(b)

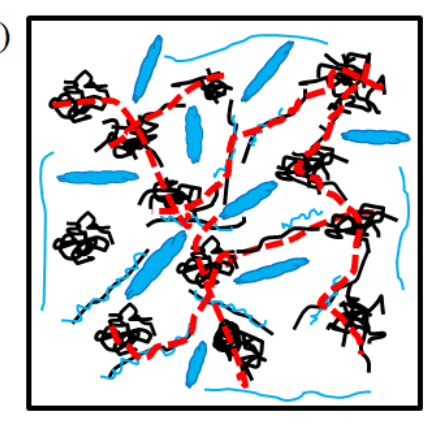

Amorphous polymer chains
Polymer crystallites

Figure 8 Schematic diagram of the conductive pathways formed in the nanocomposite with a MWCNT loading in the region of the electrical percolation threshold under SC (a) and $\mathrm{RC}(\mathrm{b})$.

\subsection{Tensile properties}

Tensile tests were carried out for the compression moulded samples to investigate the effects of the introduction of MWCNTs and the compression moulding conditions on the mechanical properties of HDPE/MWCNT nanocomposites, as shown in Table 4. Some representative tensile stress-strain curves of the nanocomposites compression moulded at 
$200{ }^{\circ} \mathrm{C}$ for 5 min followed by SC and RC are shown in Figure 9. It can be observed in Figure 9 that the nanocomposites are much more brittle than the pure HDPE due to the presence of MWCNT agglomerates which act as the stress concentration sites in the matrix. In general, regardless of the compression moulding conditions, the stress at break $\left(\sigma_{b}\right)$ and strain at break $\left(\varepsilon_{b}\right)$ decreased by over $40 \%$ and $90 \%$ respectively for all the nanocomposites with 2 and 4 wt\% MWCNTs according to Table 4. However, the stress at yield $\left(\sigma_{y}\right)$ of the nanocomposites increased by $8 \sim 10 \%$ and 12 15\% for the nanocomposites with 2 and 4 wt\% MWCNTs. In addition, the Young's modulus $(E)$ of the nanocomposites increased by about $25 \sim 50 \%$ and 110 130\% with the addition of 2 and 4 wt\% MWCNTs. The significant increases in modulus indicate an effective stress transfer between the matrix and MWCNTs. The measured moduli of the HDPE/MWCNT nanocomposites were compared with the values predicted by HalpinTsai and Mori-Tanaka composite theories.

For the randomly aligned composites, the Halpin-Tsai model can be expressed as the following formulas:

$$
\begin{gathered}
\frac{E}{E_{m}}=\frac{3}{8}\left[\frac{1+2 \alpha \eta_{L} \phi_{f}}{1-\eta_{L} \phi_{f}}\right]+\frac{5}{8}\left[\frac{1+2 \eta_{T} \phi_{f}}{1-\eta_{T} \phi_{f}}\right] \\
\eta_{T}=\frac{E_{f} / E_{m}-1}{E_{f} / E_{m}+2} \\
\eta_{L}=\frac{E_{f} / E_{m}-1}{E_{f} / E_{m}+2 \alpha}
\end{gathered}
$$

where $E, E_{f}$ and $E_{m}$ are the Young's modulus of the composites, filler and matrix, respectively. $E_{f}$ is set as $200 \mathrm{GPa}$ according to the previous literatures [18][42]. $\phi_{f}$ is the volume fraction of filler. $\alpha$ is the aspect ratio of the filler, which is set as 150 according to the MWCNT dimensional parameters. 
According to the Mori-Tanaka model and reformulated by Tandon and Weng [43], the Young's modulus of randomly aligned composites can be calculated using Equation 8-10 [34][43][44].

$$
\begin{gathered}
E=0.184 E_{11}+0.816 E_{22} \\
\frac{E_{11}}{E_{m}}=\frac{A}{A+\phi_{f}\left(A_{1}+2 v_{m} A_{2}\right)} \\
\frac{E_{22}}{E_{m}}=\frac{2 A}{2 A+\phi_{f}\left(-2 v_{m} A_{3}+\left(1-v_{m}\right) A_{4}+\left(1+v_{m}\right) A_{5} A\right)}
\end{gathered}
$$

where $v_{m}$ are the Poisson's ratio of marix, and the functions of Eshelby's tensor $\left(A, A_{1}\right.$, $A_{2}, A_{3}, A_{4}$ and $A_{5}$ ) depend on the properties of filler and matrix; more details of these equations are given elsewhere [43]. The modulus values predicted by Halpin-Tsai and MoriTanaka models are also shown in Table 4. One can see that the predicted values from both theoretical models agree well with the experimental data.

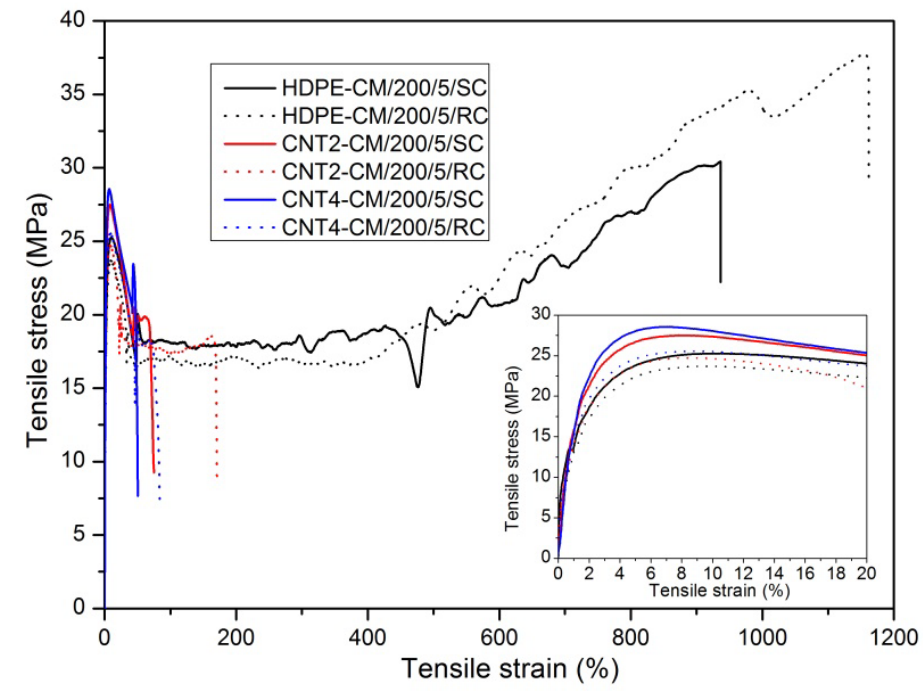

Figure 9 Tensile stress-strain curves of HDPE/MWCNT nanocomposites compression moulded at $200{ }^{\circ} \mathrm{C}$ for 5 min followed by SC and RC (Inset: a partial enlarged view of elastic and yield regions). 
As can be seen in Table 4, the tensile properties of the unfilled HDPE and HDPE/MWCNT nanocomposites are affected by the compression moulding conditions to some extent. Rapid cooling reduced the modulus and stress at yield by $10.4 \%$ and $8.8 \%$ for the unfilled HDPE samples compression moulded at $200{ }^{\circ} \mathrm{C}$ for 5 min due to a lower crystallinity level and imperfect crystallites, but the stress at break and strain at break are improved by $30.4 \%$ and $26.6 \%$ indicating that the toughness of the rapidly cooled HDPE samples is enhanced. In Table 4, heating temperature and pressing time do not show evident effects on the tensile properties of the unfilled HDPE samples because the crystallinity and crystal sizes mainly depend on the cooling condition in compression moulding. It appears that the effect of compression moulding conditions on the tensile properties of the nanocomposite containing 2 wt\% MWCNTs are more complicated. It can be seen in Table 4 that the tensile properties of the nanocomposite with $2 \mathrm{wt} \%$ MWCNTs were hardly influenced by pressing time, but modulus was improved by $12.6 \%$ when the heating temperature increased from 150 to $200{ }^{\circ} \mathrm{C}$ probably due to the formation of abundant MWCNT network structures leading to more effective stress transfer. The modulus reached a maximum value for the nanocomposite with $2 \mathrm{wt} \%$ MWCNTs compression moulded at $200{ }^{\circ} \mathrm{C}$ for 5 min followed by SC in this study, which increased by $42.0 \%$ compared with the unfilled HDPE sample. Rapid cooling reduced the stress at yield by $9.9 \%$ for the nanocomposite with 2 wt $\%$ MWCNTs compression moulded at $200{ }^{\circ} \mathrm{C}$ for $5 \mathrm{~min}$, but it significantly improved the strain at break by 119.9\% indicating cooling rate is an important parameter in determining the stress at yield and strain at break of nanocomposites with a relatively low MWCNT loading. The significant increase in the strain at break of the rapidly cooled nanocomposite containing 2 wt\% MWCNTs can be mainly attributed to the polymer matrix with enhanced toughness and smaller secondary nanotube agglomerates (Figure 3). However, rapid cooling does not show a significant effect on the modulus and stress at break of the nanocomposite containing $2 \mathrm{wt} \%$ 
MWCNTs. The stress at yield of the rapidly cooled nanocomposite with 4 wt $\%$ MWCNTs also decreased by 10.2\%. Overall, the compression moulding conditions have no significant effects on the tensile properties of the nanocomposite with 4 wt\% MWCNTs, as shown in Table 4. It indicates that the changes in the tensile properties of nanocomposites are mainly dominated by the MWCNT loading rather than the compression moulding conditions at MWCNT loadings greater than $2 \mathrm{wt} \%$.

Table 4 Effects of of MWCNT loading and compression moulding conditions on the tensile properties of HDPE/MWCNT nanocomposites.

\begin{tabular}{|c|c|c|c|c|c|c|}
\hline \multirow{2}{*}{ Sample } & \multicolumn{3}{|c|}{$E(\mathrm{MPa})$} & \multirow{2}{*}{$\sigma_{y}(\mathrm{MPa})$} & \multirow{2}{*}{$\sigma_{b}(\mathrm{MPa})$} & \multirow{2}{*}{$\varepsilon_{b}(\%)$} \\
\hline & Experimental & Halpin-Tsai & Mori-Tanaka & & & \\
\hline HDPE-CM/150/3/SC & $890.5( \pm 78.3)$ & & & $24.6( \pm 0.9)$ & $28.3( \pm 2.2)$ & $910.2( \pm 88.1)$ \\
\hline HDPE-CM/150/5/SC & $903.8( \pm 82.5)$ & & & $24.7( \pm 1.2)$ & $27.5( \pm 2.6)$ & $898.7( \pm 73.4)$ \\
\hline HDPE-CM/200/5/SC & $900.6( \pm 61.1)$ & & & $25.0( \pm 0.7)$ & $27.9( \pm 3.0)$ & $907.0( \pm 58.0)$ \\
\hline HDPE-CM/200/5/RC & 807.1( \pm 69.7$)$ & & & $22.8( \pm 0.6)$ & $36.4( \pm 1.6)$ & $1148.1( \pm 47.4)$ \\
\hline CNT2-CM/150/3/SC & $1127.2( \pm 59.5)$ & & & $27.1( \pm 0.2)$ & $17.2( \pm 0.5)$ & $73.1( \pm 16.7)$ \\
\hline CNT2-CM/150/5/SC & $1135.3( \pm 53.3)$ & & & $27.0( \pm 0.4)$ & $16.9( \pm 0.8)$ & $70.8( \pm 21.2)$ \\
\hline CNT2-CM/200/5/SC & $1278.9( \pm 27.4)$ & 1371.1 & 1381.1 & $27.3( \pm 0.2)$ & $17.1( \pm 0.7)$ & $70.0( \pm 16.0)$ \\
\hline CNT2-CM/200/5/RC & $1211.8( \pm 84.5)$ & & & $24.6( \pm 0.3)$ & $18.0( \pm 0.4)$ & $153.9( \pm 36.7)$ \\
\hline CNT4-CM/150/3/SC & $1889.2( \pm 112.6)$ & & & $28.2( \pm 0.2)$ & $16.7( \pm 0.6)$ & $47.3( \pm 11.2)$ \\
\hline CNT4-CM/150/5/SC & $1902.4( \pm 172.3)$ & & & $28.1( \pm 0.1)$ & $16.5( \pm 0.4)$ & $46.8( \pm 10.1)$ \\
\hline CNT4-CM/200/5/SC & $1905.8( \pm 149.3)$ & 1856.0 & 1814.9 & $28.4( \pm 0.3)$ & $16.6( \pm 0.3)$ & $46.9( \pm 8.8)$ \\
\hline CNT4-CM/200/5/RC & $1878.1( \pm 213.6)$ & & & $25.5( \pm 0.1)$ & $17.5( \pm 0.6)$ & $69.6( \pm 10.3)$ \\
\hline
\end{tabular}

\section{Conclusions}

Melt mixed HDPE/MWCNT nanocomposites were prepared at MWCNT loadings of $1 \sim 10 \mathrm{wt} \%$ using a twin-screw extruder and then compression moulded into sheets. The effect of compression moulding conditions on the structure, electrical and mechanical properties of the nanocomposites was systematically investigated. A network-like structure of nanotubes in 
the matrix was formed with increases in heating temperature and pressing time. The addition of MWCNTs did not have an evident influence on the crystallinity, average crystallite sizes and melting temperature, but a rapid cooling process during compression moulding reduced the crystallinity, average crystallite sizes and melting temperature slightly. Electrical resistivity tests indicate that the resistivity of all the compression moulded HDPE/MWCNT nanocomposites is lower than that of the extruded strands. According to the scaling law of classical percolation theory, the critical concentration decreases and the critical exponent increases with increasing heating temperature and pressing time during compression moulding. The composite compression moulded at a heating temperature of $200{ }^{\circ} \mathrm{C}$ and a pressing time of 5 min followed by SC shows a low critical concentration of $1.9 \mathrm{wt} \%$ and a critical exponent of 1.9. The nanocomposite with $2 \mathrm{wt} \%$ MWCNTs which is in the region of the electrical percolation threshold is very sensitive to the compression moulding conditions. Interestingly, the electrical resistivity of the rapidly cooled nanocomposite with 2 wt\% MWCNTs is 1 2 orders lower than that of the slowly cooled composites with the same MWCNT loading. This can be attributed to the lower crystallinity and smaller crystallites facilitating the formation of conductive pathways. The stress at break and strain at break of the nanocomposites drastically decrease due to the presence of MWCNT agglomerates, while the Young's modulus of the nanocomposites increase by about $25 \sim 50 \%$ and $110 \sim 130 \%$ respectively with the addition of 2 and 4 wt\% MWCNTs. The predicted moduli from HalpinTsai and Mori-Tanaka models show good agreement with the experimental results. The tensile properties of nanocomposites with 2 wt\% MWCNTs were hardly influenced by pressing time, but modulus was improved by $12.6 \%$ when heating temperature increased from $150{ }^{\circ} \mathrm{C}$ to $200{ }^{\circ} \mathrm{C}$ probably due to the formation of abundant MWCNT network structures leading to more effective stress transfer. Rapid cooling slightly reduced the stress at yield by $9.9 \%$ for the nanocomposite with 2 wt\% MWCNTs, but it significantly improved 
the strain at break by $119.9 \%$ indicating cooling rate would be an important parameter for controlling the stress at yield and strain at break of nanocomposites with a relatively low MWCNT loading. Overall, the compression moulding conditions have no significant effects on the tensile properties of the nanocomposite with $4 \mathrm{wt} \%$ MWCNTs, while the stress at yield of the rapidly cooled nanocomposite with 4 wt\% MWCNTs decreased by $10.2 \%$. It indicates that the changes in the tensile properties of nanocomposites are mainly dominated by the effect of MWCNTs rather than the compression moulding conditions at higher MWCNT loadings. This study may have significant implications for both process control and the tailoring of electrical and mechanical properties in the preparation of conductive polymer based CNT nanocomposites.

\section{Acknowledgements}

The authors would like to thank the financial support from Sichuan University Key Laboratory of Oil and Gas Field Materials (No. X151516KCL04).

\section{References}

[1] S. K. Yadav, S. S. Mahapatra, and J. W. Cho, "Tailored dielectric and mechanical properties of noncovalently functionalized carbon nanotube/poly (styrene-b-(ethyleneco-butylene)-b-styrene) nanocomposites,” Journal of Applied Polymer Science, vol. 129, no. 4, pp. 2305-2312, 2013.

[2] D. Xiang, E. Harkin-Jones, and D. Linton, "Processability, structural evolution and properties of melt processed biaxially stretched HDPE/MWCNT nanocomposites," RSC Advances, vol. 4, no. 83, pp. 44130-44140, 2014.

[3] D. Xiang, E. Harkin-Jones, and D. Linton, “Characterization and structure-property relationship of melt-mixed high density polyethylene/multi-walled carbon nanotube composites under extensional deformation,” RSC Advances, vol. 5, no. 59, pp. 4755547568, 2015.

[4] D. Xiang, E. Harkin-Jones, D. Linton, and P. Martin, "Structure, mechanical, and electrical properties of high-density polyethylene/multi-walled carbon nanotube composites processed by compression molding and blown film extrusion,” Journal of Applied Polymer Science, vol. 132, no. 42, 2015. 
[5] G. Kasaliwal, A. Göldel, and P. Pötschke, "Influence of processing conditions in smallscale melt mixing and compression molding on the resistivity and morphology of polycarbonate-MWNT composites," Journal of applied polymer science, vol. 112, no. 6, pp. 3494-3509, 2009.

[6] J. Shen, M. F. Champagne, R. Gendron, and S. Guo, “The development of conductive carbon nanotube network in polypropylene-based composites during simultaneous biaxial stretching,” European Polymer Journal, vol. 48, no. 5, pp. 930-939, 2012.

[7] C. G., "Role of processing history on the mechanical and electrical behavior of meltcompounded polycarbonate-multiwalled carbon nanotube nanocomposites," Journal of applied polymer science, vol. 132, p. 42277, 2015.

[8] G. L. Hwang, Y.-T. Shieh, and K. C. Hwang, "Efficient Load Transfer to PolymerGrafted Multiwalled Carbon Nanotubes in Polymer Composites," Advanced Functional Materials, vol. 14, no. 5, pp. 487-491, 2004.

[9] D. Gomes, M. R. Loos, M. H. Wichmann, A. de la Vega, and K. Schulte, "Sulfonated polyoxadiazole composites containing carbon nanotubes prepared via in situ polymerization,” Composites Science and Technology, vol. 69, no. 2, pp. 220-227, 2009.

[10] Q. Wang, J. Dai, W. Li, Z. Wei, and J. Jiang, “The effects of CNT alignment on electrical conductivity and mechanical properties of SWNT/epoxy nanocomposites,” Composites Science and Technology, vol. 68, no. 7, pp. 1644-1648, 2008.

[11] T. McNally, P. Pötschke, P. Halley, M. Murphy, D. Martin, S. E. J. Bell, G. P. Brennan, D. Bein, P. Lemoine, and J. P. Quinn, "Polyethylene multiwalled carbon nanotube composites,” Polymer, vol. 46, no. 19, pp. 8222-8232, 2005.

[12] H.-B. Zhang, W.-G. Zheng, Q. Yan, Y. Yang, J.-W. Wang, Z.-H. Lu, G.-Y. Ji, and Z.-Z. $\mathrm{Yu}$, "Electrically conductive polyethylene terephthalate/graphene nanocomposites prepared by melt compounding,” Polymer, vol. 51, no. 5, pp. 1191-1196, 2010.

[13] C. McClory, T. McNally, M. Baxendale, P. Pötschke, W. Blau, and M. Ruether, "Electrical and rheological percolation of PMMA/MWCNT nanocomposites as a function of CNT geometry and functionality,” European Polymer Journal, vol. 46, no. 5, pp. 854-868, 2010.

[14] R. Socher, B. Krause, M. T. Müller, R. Boldt, and P. Pötschke, "The influence of matrix viscosity on MWCNT dispersion and electrical properties in different thermoplastic nanocomposites,” Polymer, vol. 53, no. 2, pp. 495-504, 2012.

[15] B. Mayoral, J. Lopes, and T. McNally, "Influence of Processing Parameters During Small-Scale Batch Melt Mixing on the Dispersion of MWCNTs in a Poly (propylene) Matrix,” Macromolecular Materials and Engineering, vol. 299, no. 5, pp. 609-621, 2014.

[16] C. McClory, P. Pötschke, and T. McNally, "Influence of Screw Speed on Electrical and Rheological Percolation of Melt-Mixed High-Impact Polystyrene/MWCNT

Nanocomposites,” Macromolecular Materials and Engineering, vol. 296, no. 1, pp. 59- 
69, 2011.

[17] B. Mayoral, G. Garrett, and T. McNally, "Influence of Screw Profile Employed During Melt Mixing on the Micro-scale Dispersion of MWCNTs in Poly (propylene)," Macromolecular Materials and Engineering, vol. 299, no. 6, pp. 748-756, 2014.

[18] M. Morcom, K. Atkinson, and G. P. Simon, "The effect of carbon nanotube properties on the degree of dispersion and reinforcement of high density polyethylene," Polymer, vol. 51, no. 15, pp. 3540-3550, 2010.

[19] P. Verge, S. Benali, L. Bonnaud, A. Minoia, M. Mainil, R. Lazzaroni, and P. Dubois, "Unpredictable dispersion states of MWNTs in HDPE: A comparative and comprehensive study,” European Polymer Journal, vol. 48, pp. 677-683, 2012.

[20] J. Yang, K. Wang, H. Deng, F. Chen, and Q. Fu, "Hierarchical structure of injectionmolded bars of HDPE/MWCNTs composites with novel nanohybrid shish-kebab," Polymer, vol. 51, no. 3, pp. 774-782, 2010.

[21] F. Tao, L. Bonnaud, D. Auhl, B. Struth, P. Dubois, and C. Bailly, "Influence of shearinduced crystallization on the electrical conductivity of high density polyethylene carbon nanotube nanocomposites,” Polymer, vol. 53, no. 25, pp. 5909-5916, 2012.

[22] O. Valentino, M. Sarno, N. G. Rainone, M. R. Nobile, P. Ciambelli, H. C. Neitzert, and G. P. Simon, "Influence of the polymer structure and nanotube concentration on the conductivity and rheological properties of polyethylene/CNT composites," Physica E: Low-dimensional Systems and Nanostructures, vol. 40, no. 7, pp. 2440-2445, 2008.

[23] B. Xu, J. Leisen, H. W. Beckham, R. Abu-Zurayk, E. Harkin-Jones, and T. McNally, "Evolution of clay morphology in polypropylene/montmorillonite nanocomposites upon equibiaxial stretching: a solid-state NMR and TEM approach,” Macromolecules, vol. 42, no. 22, pp. 8959-8968, 2009.

[24] S. Xie, E. Harkin-Jones, Y. Shen, P. Hornsby, M. McAfee, T. McNally, R. Patel, H. Benkreira, and P. Coates, "Quantitative characterization of clay dispersion in polypropylene-clay nanocomposites by combined transmission electron microscopy and optical microscopy,” Materials Letters, vol. 64, no. 2, pp. 185-188, 2010.

[25] R. Abu-Zurayk and E. Harkin-Jones, "The influence of processing route on the structuring and properties of high-density polyethylene (HDPE)/clay nanocomposites," Polymer Engineering \& Science, vol. 52, no. 11, pp. 2360-2368, 2012.

[26] R. Abu-Zurayk, E. Harkin-Jones, T. McNally, G. Menary, P. Martin, C. Armstrong, and M. McAfee, "Structure-property relationships in biaxially deformed polypropylene nanocomposites,” Composites Science and Technology, vol. 70, no. 9, pp. 1353-1359, 2010.

[27] T. Villmow, S. Pegel, P. Pötschke, and U. Wagenknecht, "Influence of injection molding parameters on the electrical resistivity of polycarbonate filled with multiwalled carbon nanotubes,” Composites Science and Technology, vol. 68, no. 3, pp. 777- 
789, 2008.

[28] D. Lellinger, D. Xu, A. Ohneiser, T. Skipa, and I. Alig, "Influence of the injection moulding conditions on the in-line measured electrical conductivity of polymer-carbon nanotube composites,” physica status solidi (b), vol. 245, no. 10, pp. 2268-2271, 2008.

[29] D.-R. Yu and G.-H. Kim, "Effect of processing parameters on the surface resistivity of ethylene-vinyl acetate copolymer/multiwalled carbon nanotube nanocomposites,” Journal of Applied Polymer Science, vol. 124, no. 4, pp. 2962-2967, 2012.

[30] T. Villmow, P. Pötschke, S. Pegel, L. Häussler, and B. Kretzschmar, "Influence of twinscrew extrusion conditions on the dispersion of multi-walled carbon nanotubes in a poly (lactic acid) matrix,” Polymer, vol. 49, no. 16, pp. 3500-3509, 2008.

[31] W. Luo, N. Zhou, Z. Zhang, and H. Wu, "Effects of vibration force field on structure and properties of HDPE/CaCO $<$ sub $>3</$ sub $>$ nanocomposites," Polymer testing, vol. 25, no. 1, pp. 124-129, 2006.

[32] B. Wunderlich, Macromolecular physics, volume 3-crystal melting. New york: Academic Press, 1980.

[33] F. Nanni, B. Mayoral, F. Madau, G. Montesperelli, and T. McNally, "Effect of MWCNT alignment on mechanical and self-monitoring properties of extruded PETMWCNT nanocomposites," Composites Science and Technology, vol. 72, pp. 11401146, 2012.

[34] M. Pöllänen, S. Pirinen, M. Suvanto, and T. T. Pakkanen, "Influence of carbon nanotube-polymeric compatibilizer masterbatches on morphological, thermal, mechanical, and tribological properties of polyethylene," Composites Science and Technology, vol. 71, no. 10, pp. 1353-1360, 2011.

[35] O. Zhou, R. Fleming, D. Murphy, C. Chen, R. Haddon, A. Ramirez, and S. Glarum, "Defects in carbon nanostructures," Science, vol. 263, no. 5154, pp. 1744-1747, 1994.

[36] P. Kalakonda, G. S. Iannacchione, M. Daly, G. Y. Georgiev, Y. Cabrera, R. Judith, and P. Cebe, "Calorimetric study of nanocomposites of multiwalled carbon nanotubes and isotactic polypropylene polymer," Journal of Applied Polymer Science, vol. 130, no. 1, pp. 587-594, 2013.

[37] R. Haggenmueller, J. E. Fischer, and K. I. Winey, "Single wall carbon nanotube/polyethylene nanocomposites: nucleating and templating polyethylene crystallites,” Macromolecules, vol. 39, no. 8, pp. 2964-2971, 2006.

[38] R. Zhang, A. Dowden, H. Deng, M. Baxendale, and T. Peijs, “Conductive network formation in the melt of carbon nanotube/thermoplastic polyurethane composite," Composites Science and Technology, vol. 69, no. 10, pp. 1499-1504, 2009.

[39] J. Du, L. Zhao, Y. Zeng, L. Zhang, F. Li, P. Liu, and C. Liu, “Comparison of electrical properties between multi-walled carbon nanotube and graphene nanosheet/high density polyethylene composites with a segregated network structure,” Carbon, vol. 49, no. 4, 
pp. 1094-1100, 2011.

[40] Y. Xi, A. Yamanaka, Y. Bin, and M. Matsuo, "Electrical properties of segregated ultrahigh molecular weight polyethylene/multiwalled carbon nanotube composites," Journal of applied polymer science, vol. 105, no. 5, pp. 2868-2876, 2007.

[41] C. Li, E. T. Thostenson, and T.-W. Chou, "Dominant role of tunneling resistance in the electrical conductivity of carbon nanotube-based composites,” Applied Physics Letters, vol. 91, no. 22, pp. 223114-223114, 2007.

[42] Z. Jiang, P. Hornsby, R. McCool, and A. Murphy, "Mechanical and thermal properties of polyphenylene sulfide/multiwalled carbon nanotube composites,” Journal of Applied Polymer Science, vol. 123, no. 5, pp. 2676-2683, 2011.

[43] T. G.P. and W. G.J., "The effect of aspect ratio of inclusions on the elastic properties of unidirectionally aligned composites,” Polymer composites, vol. 5, no. 4, pp. 327-333, 1984.

[44] T. Fornes and D. Paul, "Modeling properties of nylon 6/clay nanocomposites using composite theories,” Polymer, vol. 44, no. 17, pp. 4993-5013, 2003. 
Table of Content 